\title{
Performance characteristics of the light-initiated chemiluminescent assay for quantitative determination of progesterone
}

\author{
Kai Chen ${ }^{1 \#}$, Dan Wu ${ }^{1 \#}$, Mengdan Gao ${ }^{1}$, Yongfeng $\operatorname{Yan}^{1}$, Huiqiang $\mathrm{Li}^{2}$ \\ ${ }^{1}$ Department of Clinical Laboratory, Tianjin Beichen Hospital, Tianjin, China; ${ }^{2}$ Department of Clinical Immunology, School of Medical Laboratory, \\ Tianjin Medical University, Tianjin, China \\ Contributions: (I) Conception and design: K Chen, D Wu; (II) Administrative support: K Chen; (III) Provision of study materials or patients: Y Yan; \\ (IV) Collection and assembly of data: M Gao; (V) Data analysis and interpretation: H Li; (VI) Manuscript writing: All authors; (VII) Final approval of \\ manuscript: All authors. \\ \#These authors contributed equally to this work. \\ Correspondence to: Huiqiang Li. Department of Clinical Immunology, School of Medical Laboratory, Tianjin Medical University, Hexi District, \\ Tianjin, China. Email: lhq@tmu.edu.cn.
}

Background: To study the performance of quantitative determination of progesterone by light-initiated chemiluminescent assay (LICA).

Methods: Clinical samples of serum were used for detection of progesterone by LICA. The precision study was performed according to Clinical and Laboratory Standards Institute (CLSI) EP15-A3, the linear range validation was performed according to CLSI EP06-A, accuracy was evaluated according to CLSI EP9-A3, and the performance of detection capability was confirmed according to CLSI EP17-A2. All data were analyzed using SPSS software. Function regression analysis was performed by OriginPro software.

Results: The LICA-800 system exhibited low coefficients of variation (CVs) and high reproducibility, and the calculated synthetic CV was $2.16 \%$. The access progesterone assay showed excellent linearity in the assay measuring range $(0.37-40 \mathrm{ng} / \mathrm{mL})$ using the polynomial regression method in accordance with CLSI EP06-A. Bias assessment was used to verify accuracy, and the percentage deviation met the quality requirements of the laboratory's allowable deviation of $10.00 \%$. In terms of the detection capability of LICA, the calculated limit of blank $(\mathrm{LoB})$ was $0.046 \mathrm{ng} / \mathrm{mL}$, limit of detection $(\mathrm{LoD})$ was $0.057 \mathrm{ng} / \mathrm{mL}$, and the limit of quantitation (LoQ) value was $0.161 \mathrm{ng} / \mathrm{mL}$.

Conclusions: The competitive LICA provided a highly sensitive, accurate and precise method for measuring serum progesterone level.

Keywords: Progesterone; light-initiated chemiluminescent assay (LICA); quantitative assay; analysis performance

Submitted Apr 28, 2021. Accepted for publication Aug 26, 2021.

doi: 10.21037/atm-21-3119

View this article at: https://dx.doi.org/10.21037/atm-21-3119

\section{Introduction}

Progesterone (P4) is a steroid hormone that plays an important role in reproductive function (1). It is produced by the corpus luteum during early pregnancy, and mainly used clinically to determine ovulation, for progesterone treatment monitoring and early pregnancy evaluation $(2,3)$. In addition, $\mathrm{P} 4$ can also prevent and treat osteoporosis in women, prior considers that $\mathrm{P} 4$ is essential for development of adolescent peak bone mineral density (4). P4 can also induce neuroprotection (5). Thus, accurate detection of $\mathrm{P} 4$ is hugely important in clinical work.

The light-initiated chemiluminescent assay (LICA) is an emerging homogeneous quantitative immunoassay technology. Previous studies have shown good repeatability 
and intermediate imprecision in detecting total testosterone, estradiol, thyroid-stimulating hormone (TSH) etc. by the $\operatorname{LICA}(6,7)$.

In this study, we evaluated the performance of LICA for quantitative determination of $\mathrm{P} 4$ in human serum. We present the following article in accordance with the MDAR reporting checklist (available at https://dx.doi.org/10.21037/ atm-21-3119).

\section{Methods}

\section{Apparatus and reagents}

All clinical samples were serum samples. The study was conducted in accordance with the Declaration of Helsinki (as revised in 2013). The study was approved by the ethics committee of Tianjin Beichen Hospital. Informed consent was obtained from all human participants. All the tests were carried out using the LICA 800 (China).

\section{Precision study}

The precision study was performed according to the according to CLSI EP15-A3: User Verification of Precision and Estimation of Bias, 3rd Edition (8).

In terms of sample selection, according to the precision confirmation report provided by the reagent manufacturer, the samples that were close to the concentration value of the imprecision parameters confirmed by the manufacturer and consistent with the matrix were selected as verification samples, in which: PC Land PC $\mathrm{H}$ are low-value and high-value quality control products provided by the manufacturer; Sample 1, Sample 2 are the clinical serum samples; Bio- $\mathrm{M}$ and Bio-H are intermediate and high-value quality control products from the Bio-Rad company.

\section{Linearity study}

The linear range validation was performed according to CLSI EP06-A: Evaluation of the Linearity of Quantitative Measurement Procedures: A Statistical Approach; Approved Guideline (9).

Clinical samples with a linear range of $0.37-40 \mathrm{ng} / \mathrm{mL}$ were collected, and high-value samples (HV) and low-value samples (LV) were diluted according to a certain proportion. Five samples were obtained: $1 \mathrm{~mL} \mathrm{LV}$ for sample 1; $0.75 \mathrm{~mL} \mathrm{LV}+0.25 \mathrm{~mL} \mathrm{HV}$ for sample 2; $0.50 \mathrm{~mL} \mathrm{LV} \mathrm{+}$ $0.50 \mathrm{~mL} \mathrm{HV}$ for sample $3 ; 0.25 \mathrm{~mL} \mathrm{LV}+0.75 \mathrm{~mL} \mathrm{HV}$ for sample 4; and $1 \mathrm{~mL} \mathrm{HV}$ for sample 5.

\section{Accuracy study}

Accuracy was evaluated according to CLSI EP9-A3: Measurement Procedure Comparison and Bias Estimation using Patient Samples; Approved Guideline 3rd Edition Scheme (10). Numerical consistency was compared with Beckman. All samples were tested three times before the mean value was taken.

\section{Detectability performance confirmation}

The performance of detection capability shall be confirmed according to CLSI EP17-A2: Evaluation of Detection Capability for Clinical Laboratory Measurement Procedures; Approved Guideline, 2nd Edition (11).

\section{Statistical analysis}

The data were analyzed using SPSS software. Function regression analysis was performed by Originpro software. $\mathrm{P}<0.05$ was considered statistically significant.

\section{Results}

\section{Precision verification}

The results are shown in Table 1. Paired $t$-test was conducted between the sample concentration and the concentration in the precision confirmation report provided by the manufacturer $(\mathrm{T}=1.179, \mathrm{P}=0.304)$. There was no significant difference between the concentration value selected and the concentration value provided by the manufacturer, so the sample concentration had been selected appropriately. The PC LV, Sample 2, Bio-M and Bio-HV samples were less than the imprecision of the manufacturer's declaration and passed directly; the PC HV and Sample 1, which were greater than the imprecision during the manufacturer's declaration, passed the verification by calculating the verification value (UVL), and finally they were less than the UVL of the imprecision according to the manufacturer's declaration.

In terms of the precision test data set: the standard deviation (SD) and CV of each sample were calculated after four times of repeated detection. The $\mathrm{CV}$ trend was relatively constant among repeated testing of cross-grade samples, and the calculated synthetic $\mathrm{CV}$ was $2.16 \%$, 
Table 1 Precision verification data $(\mathrm{ng} / \mathrm{mL})$

\begin{tabular}{|c|c|c|c|c|c|c|c|}
\hline Sample & $\begin{array}{c}\text { Mean value of } \\
\text { detection }\end{array}$ & \multicolumn{2}{|c|}{ Repeatability } & \multicolumn{2}{|c|}{ Intermediate imprecision } & $\begin{array}{l}\text { Manufacturer's } \\
\text { declared CV (\%) }\end{array}$ & UVL \\
\hline PC LV & 4.12 & 0.156 & 3.79 & 0.166 & 4.01 & 4.26 & - \\
\hline PC HV & 19.77 & 0.812 & 4.11 & 0.812 & 4.11 & 3.68 & 5.59 \\
\hline Sample 1 & 11.80 & 0.499 & 4.23 & 0.499 & 4.23 & 4.02 & 5.98 \\
\hline Bio-M & 5.30 & 0.224 & 4.23 & 0.301 & 5.68 & 5.91 & - \\
\hline Bio-H & 20.68 & 0.956 & 4.62 & 1.056 & 5.11 & 5.50 & - \\
\hline
\end{tabular}

Table 2 Summary of curve estimation results

\begin{tabular}{|c|c|c|c|c|c|c|}
\hline Order & $\begin{array}{l}\text { Coefficient } \\
\text { symbol }\end{array}$ & $\begin{array}{l}\text { Coefficient } \\
\text { value }\end{array}$ & $\begin{array}{c}\text { Coefficient standard } \\
\text { error }\end{array}$ & $t$-test & $P$ value & $\begin{array}{c}\text { Standard error of regression } \\
\text { coefficient }\end{array}$ \\
\hline \multirow[t]{2}{*}{ First order } & $\mathrm{a}$ & 0.210 & 0.249 & 2.857 & 0.009 & 0.677 \\
\hline & b1 & 0.976 & 0.010 & 94.362 & 0.000 & \\
\hline Second order & a & 0.167 & 0.266 & 0.629 & 0.536 & 0.565 \\
\hline \multirow[t]{3}{*}{ Third order } & a & 0.067 & 0.300 & 0.225 & 0.824 & 0.571 \\
\hline & b1 & 1.124 & 0.073 & 15.391 & 0.000 & \\
\hline & b2 & -0.006 & 0.005 & -1.286 & 0.213 & \\
\hline
\end{tabular}

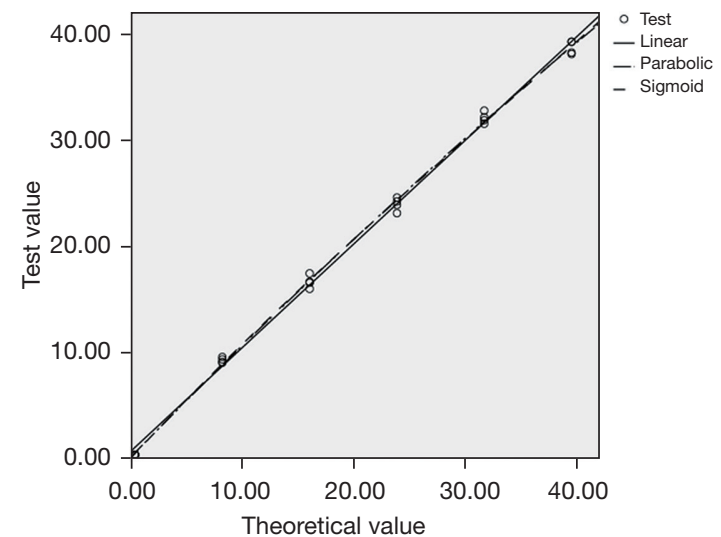

Figure 1 Linear regression fitting curve ( $\mathrm{X}$ is the theoretical value; $\mathrm{Y}$ is the measured value). which was less than the allowed imprecision (7.50\%) of the project established by our laboratory, and so the precision verification was passed.

\section{Linearity test}

SPSS software was used to input the theoretical value and test value of the data set. The regression analysis curve estimation is shown in Table 2. The optimal fitting equation was $\mathrm{Y}=-0.002 \mathrm{X}^{2}+1.075 \mathrm{X}+0.167$ ( $\mathrm{X}$ is the theoretical value), and the curve is shown in Figure 1.

As for the judgment of the nonlinear degree of the data group, the results are shown in Table 3. The fitting values of the optimal fitting equation and the first-order 
Table 3 EP6-A2 judgment of nonlinear degree

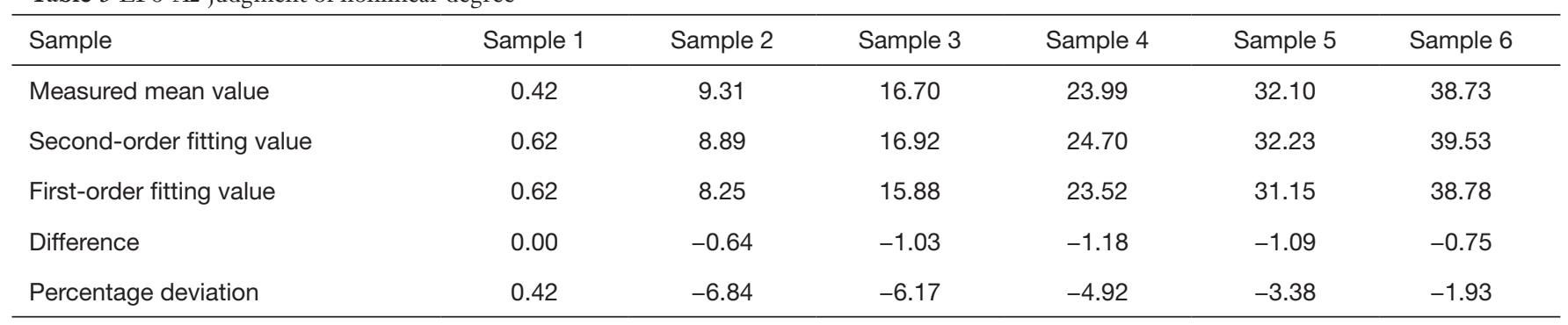
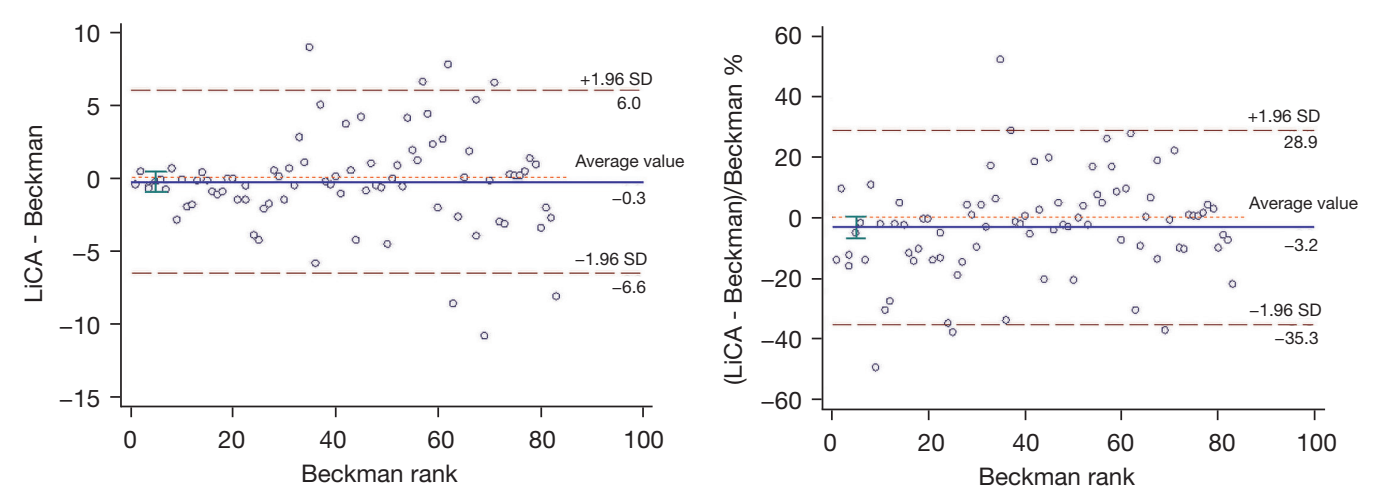

Figure 2 Bland-Altman graph: the vertical axis of (left) is the deviation, and the vertical axis of (right) is the percentage deviation.

equation were calculated and compared with the measured mean value; the percentage deviation was calculated and compared with the allowable deviation of $10.00 \%$. The results are shown in Table 3, which are all tests passed.

\section{Accuracy evaluation}

\section{Outlier test and homogeneity analysis of each data segment}

According to the quality requirements of the quality assessment program of the Royal Society of Pathologists, $\mathrm{P} 4 \leq 10 \mathrm{nmol} / \mathrm{L}(3.15 \mathrm{ng} / \mathrm{mL})$, and the allowable deviation is $\pm 2 \mathrm{nmol} / \mathrm{L}(0.63 \mathrm{ng} / \mathrm{mL})$. The Beckman test result was $<3.15 \mathrm{ng} / \mathrm{mL}$, which was not included in the analysis. A total of 33 cases were not included in the analysis, and 30 cases $(90.91 \%)$ met the requirements of the allowable deviation.

The remaining data group used the generalized extreme studentized deviate (ESD) method $(\alpha=0.01)$ to eliminate outliers, no outliers, and the 83 valid data groups.

\section{Preliminary estimation of bias}

A Bland-Altman diagram was drawn to observe the characteristics of the paired data of the two groups (Figure 2). The data group basically showed the characteristics of constant CV. Shapiro-Wilk test showed that the data group was normal, $w=0.9706(\mathrm{P}=0.0537)$. The normality was accepted, the bias was expressed by the mean of percentage deviation, and the bias was $-3.24 \%$ ( $-5.03 \%$ to $-1.45 \%)$.

\section{Regression analysis}

The best models (OLR, WLS, Deming and PassingBablock) were used for regression analysis of the data group. The specific results are shown in Table 4. The best fitting curve was WLS: $y=1.005 \mathrm{x}-0.379$; the Spearman correlation coefficient was 0.940 (Table 4).

\section{Calculation of bias at medical decision-making level}

This was evaluated by substituting the clinical attention diagnostic points $5.09,11.52$ and $18.62 \mathrm{ng} / \mathrm{mL}$ into the above equation with the least proportional bias. The results are shown in Table 5. The percentage deviation of each concentration point met the quality requirements of the laboratory's allowable deviation of $10.00 \%$.

\section{Detectability performance confirmation}

\section{LoB}

We used the diluent provided by the manufacturer for each 
Table 4 Summary of four linear fitting models

\begin{tabular}{lllll}
\hline Regression model & Regression curve & Slope 95\% Cl & Intercept 95\% Cl & Proportional bias (\%) \\
\hline OLR & $\mathrm{Y}=1.004 \mathrm{X}-0.354$ & $0.930-1.078$ & -1.944 to 1.236 & -7.0 to 7.8 \\
WLS & $\mathrm{Y}=1.005 \mathrm{X}-0.379$ & $1.001-1.009$ & -0.464 to -0.295 & 0.1 to 0.9 \\
Deming & $\mathrm{Y}=1.063 \mathrm{X}-1.482$ & $0.991-1.135$ & -2.532 to -0.432 & -0.9 to 13.5 \\
Passing-Bablok & $\mathrm{Y}=1.057 \mathrm{X}-1.363$ & $1.008-1.111$ & -2.083 to -0.299 & 0.8 to 11.1 \\
\hline
\end{tabular}

$95 \% \mathrm{Cl}, 95 \%$ confidence interval.

Table 5 Summary of bias at the medical decision-making level

\begin{tabular}{lccr}
\hline Determining level $(\mathrm{ng} / \mathrm{mL})$ & Estimated value $(\mathrm{ng} / \mathrm{mL})$ & Deviation $(\mathrm{ng} / \mathrm{mL})$ & Percentage deviation $(\%)$ \\
\hline 5.09 & 4.74 & -0.35 & -7.20 \\
11.52 & 11.20 & -0.32 & -2.83 \\
18.62 & 18.33 & -0.29 & -1.55 \\
\hline
\end{tabular}

Table 6 Summary of LoD performance validation data

\begin{tabular}{lcc}
\hline Sample & Mean value $(\mathrm{ng} / \mathrm{mL})$ & $\mathrm{SD}(\mathrm{ng} / \mathrm{mL})$ \\
\hline 1 & 0.046 & 0.0062 \\
2 & 0.065 & 0.0070 \\
3 & 0.125 & 0.0092 \\
4 & 0.258 & 0.0162 \\
5 & 0.311 & 0.0188 \\
\hline
\end{tabular}

LoD, limit of detection.

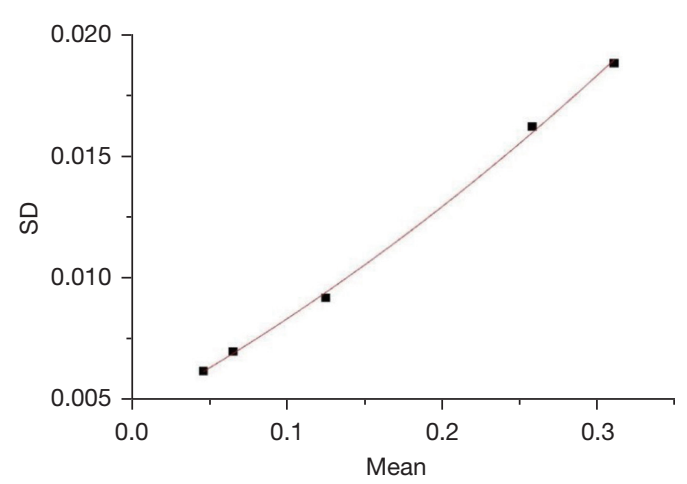

Figure 3 Precision curve (x-axis is each average analyte concentration; $\mathrm{y}$-axis is intralaboratory variation).

sample, and each of the 5 samples was repeatedly tested 12 times, for a total of 60 test results. The Curve Calculator software provided by the manufacturer was used to fit the results of the cubic spline algorithm.

Sort the 60 test results according to size, calculated the percentile $(\mathrm{PctB})$ of the result distribution of blank specimens, and $\alpha=0.05, \operatorname{PctB}=1-\alpha=0.95$ were required. The corresponding arrangement position for calculating the percentile was as follows: arrangement position $=0.5+$ $(\mathrm{B} \times \mathrm{PctB})$, where $\mathrm{B}$ is the total number of samples, and the 60 test results are arranged at 57.5; LoB should be calculated according to the 57 th and 58th digits, namely $\mathrm{LoB}=\mathrm{X} 57+0.5(\mathrm{X} 58-\mathrm{X} 57)$.

In this study, $\mathrm{X} 57=0.16$ and $\mathrm{X} 58=0.17$, so the calculated LoB was $0.046 \mathrm{ng} / \mathrm{mL}$.

\section{LoD}

We used the diluent provided by the manufacturer to dilute the LV clinical samples to obtain serial concentration samples. Each sample was tested for 3 days, and each sample was tested 4 times a day. The mean value and $\mathrm{CV}$ of each sample were calculated and shown in Table 6 .

The homogeneity of variance test was carried out for the above groups of data. The $\mathrm{F}$ value was $248.3, \mathrm{P}=0.000$, and variance was uneven. $\mathrm{LoD}$ was calculated using the precision curve scheme with Originpro software. The results are shown in Figure 3. The specific curve selection method was consistent with the verification of linear range, and the final precision curve was $Y=0.0385 \mathrm{X}^{2}+0.0344 \mathrm{X}+0.0045$.

Substituting $\mathrm{LoB}$ as $\mathrm{X}$ into the above equation, $S D_{W L}$ $=0.018$, using the regression line variance to calculate the $S D_{W L}$ value under the corresponding measured 
Table 7 Measured concentration (MC), $\mathrm{SD}_{W L}$ and trial $\mathrm{LoD}$ values and bias

\begin{tabular}{lccc}
\hline $\mathrm{MC}$ & $\mathrm{SD}_{W L}(\mathrm{ng} / \mathrm{mL})$ & Trial LoD $(\mathrm{ng} / \mathrm{mL})$ & Bias $(\mathrm{ng} / \mathrm{mL})$ \\
\hline 0.050 & 0.006 & 0.056 & 0.006 \\
0.052 & 0.006 & 0.057 & 0.005 \\
0.054 & 0.006 & 0.057 & 0.003 \\
0.056 & 0.007 & 0.057 & 0.001 \\
0.057 & 0.007 & 0.057 & 0.000 \\
0.058 & 0.007 & 0.057 & -0.001 \\
0.059 & 0.007 & 0.057 & -0.002 \\
\hline
\end{tabular}

LoD, limit of detection.

Table 8 Summary of LoQ performance validation data

\begin{tabular}{lcc}
\hline Sample & Mean value $(\mathrm{ng} / \mathrm{mL})$ & CV $(\%)$ \\
\hline 1 & 0.032 & 16.76 \\
2 & 0.052 & 14.21 \\
3 & 0.075 & 11.22 \\
4 & 0.099 & 9.53 \\
5 & 0.121 & 8.26 \\
6 & 0.142 & 8.02 \\
7 & 0.265 & 6.25 \\
8 & 0.398 & 4.21 \\
9 & 0.523 & 3.99 \\
\hline
\end{tabular}

LoQ, limit of quantitation.

concentration (MC). then used the $S D_{W L}$ value obtained to calculate the test $\mathrm{LoD}$ value. The bias was calculated by subtracting the $M C$ value from the test $L o D$ value. When the bias changes from positive to negative, the step length between the two concentrations can be reduced to determine the test $\mathrm{LoD}$ value when the bias is equal to 0 . The test $\mathrm{LoD}$ value was the final $\mathrm{LoD}$ value. The results are shown in Table 7; LoD $=0.057 \mathrm{ng} / \mathrm{mL}$.

\section{LoQ}

Thelow-value clinical samples were diluted with the diluent provided by the manufacturer. Each sample was tested for 20 days, and two analysis batches were made every day, each batch and each sample were tested twice. The CVs and mean values are shown in Table 8.

The functional regression analysis was carried out using Originpro software. The allowable imprecision was

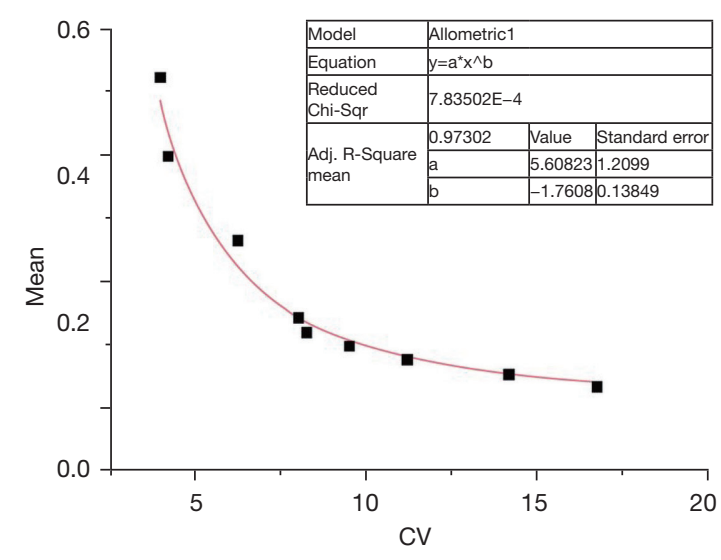

Figure 4 Function curve (x-axis is the coefficient of variation; $y$-axis is mean value).

derived as $7.50 \%$ based on the current technical level. The regression curve is shown in Figure 4. The available function was $\mathrm{Y}=5.6082 \mathrm{X}-1.761 ; \mathrm{Y}=0.161 \mathrm{ng} / \mathrm{mL}$ was obtained by substituting the coefficient of admissible variation as $\mathrm{X}$ in the equation.

In summary, the $\mathrm{LoQ}$ value was $0.161 \mathrm{ng} / \mathrm{mL}$ (the allowable error is $7.50 \%$ ).

\section{Discussion}

In this study, we used established LICA equipment for quantitative detection of $\mathrm{P} 4$ in human serum. The basic principle of light-induced chemiluminescence is a homogeneous immunoassay. The antigen or antibody on the surface of the luminescent particle forms an immune complex with the antigen or antibody to be tested in the liquid phase, and then the two types of particles are pulled closer by combining the biotin-avidin system with photosensitive particles coated with avidin. Under laser excitation, the energy transfer of ionic oxygen between particles occurs, and the high-energy red light is generated. The photon number is converted into a target molecular concentration by single photon counter and mathematical fitting. In contrast, when there is no target molecule in the sample, the immune complex cannot form between the two particles. The distance between the two particles exceeds the range of ionic oxygen transmission, the ionic oxygen is rapidly quenched, and no high-energy red light signal is generated. The $\mathrm{P} 4$ concentration in human serum negatively correlates with the signal value and can be calculated quantitatively according to the calibration curve.

As a quantitative assay, the advantages of the LICA are 
as follows: long-arm biotin-labeled progesterone, in which biotin is a small molecule, coupled with small molecular progesterone, has little effect on biological activities. Second, biotin-labeled progesterone is coupled through a specific chemical bond, giving the labeled progesterone better specific activity, which is helpful for improving the sensitivity of the analysis. In contrast, when labeled with a macromolecular enzyme protein, the immune activity of progesterone is affected. Finally, the LICA is based on a one-step homogeneous immunoreaction, and the homogeneous environment does not requiring washing processes, which avoids the possibility of crosscontamination. Yang et al. consider this an important factor responsible for the increased precision because it contributes to a more stable reaction system (12).

Based on the results presented here, we confirmed low $\mathrm{CVs}$ and high reproducibility (repeatability $\mathrm{CV} \leq 7.5 \%$ ) in the detection of $\mathrm{P} 4$ on the LICA- 800 system, and precision was verified. Furthermore, the access progesterone assay showed excellent linearity in the assay measuring range $(0.37-40 \mathrm{ng} / \mathrm{mL})$ using the polynomial regression method in accordance with CLSI EP06-A. Bias assessment was used to verify the accuracy, and the percentage deviation met the quality requirements of the laboratory's allowable deviation of $10.00 \%$, which means that the LICA is accurate for progesterone quantification. In addition, we confirmed the detection capability of LICA: the calculated LoB was $0.046 \mathrm{ng} / \mathrm{mL}$, LoD was $0.057 \mathrm{ng} / \mathrm{mL}$, and the $\mathrm{LoQ}$ value was $0.161 \mathrm{ng} / \mathrm{mL}$, which means that LICA is sensitive in detecting P4. Therefore, the LICA exhibited good analytical performance and fulfilled the accuracy requirements.

Chemiluminescence immunoassay is widely used in clinical laboratories. Though with high sensitivity and accuracy, it also has certain disadvantages. For example, the above immunoassay requires several washing steps as well as solid-phase immobilization of antibodies, which is time-consuming and laborious (13). Similarly, liquid chromatography-tandem mass spectrometry (LC-MS/ MS) is also an emerging technology for the detection of small molecular hormones $(14,15)$, but its high cost and low degree of automation limit its popularity and application in clinical laboratories. While LICA has shown good repeatability and intermediate imprecision in detecting progesterone, total testosterone, estradiol, TSH etc. $(6,7)$. All these findings confirm the practicability of this assay in detecting small molecular hormones. From this point of view, LICA may be more suitable for the routine detection of small molecular hormones such as progesterone.

\section{Conclusions}

The competitive LICA provided a rapid, highly sensitive, accurate and precise method for the measurement of serum progesterone. The LICA is a promising assay for clinical application.

\section{Acknowledgments}

Funding: None.

\section{Footnote}

Reporting Checklist: The authors have completed the MDAR reporting checklist. Available at https://dx.doi. org/10.21037/atm-21-3119

Data Sharing Statement: Available at https://dx.doi. org/10.21037/atm-21-3119

Conflicts of Interest: All authors have completed the ICMJE uniform disclosure form (available at https://dx.doi. org/10.21037/atm-21-3119). The authors have no conflicts of interest to declare.

Ethical Statement: The authors are accountable for all aspects of the work in ensuring that questions related to the accuracy or integrity of any part of the work are appropriately investigated and resolved. The study was conducted in accordance with the Declaration of Helsinki (as revised in 2013). The study was approved by the ethics committee of Tianjin Beichen Hospital. Informed consent was obtained from all human participants.

Open Access Statement: This is an Open Access article distributed in accordance with the Creative Commons Attribution-NonCommercial-NoDerivs 4.0 International License (CC BY-NC-ND 4.0), which permits the noncommercial replication and distribution of the article with the strict proviso that no changes or edits are made and the original work is properly cited (including links to both the formal publication through the relevant DOI and the license). See: https://creativecommons.org/licenses/by-nc-nd/4.0/.

\section{References}

1. Goletiani NV, Keith DR, Gorsky SJ. Progesterone: review of safety for clinical studies. Exp Clin Psychopharmacol 
2007;15:427-44.

2. Romero R, Conde-Agudelo A, Da Fonseca E, et al. Vaginal progesterone for preventing preterm birth and adverse perinatal outcomes in singleton gestations with a short cervix: a meta-analysis of individual patient data. Am J Obstet Gynecol 2018;218:161-80.

3. Romero R, Nicolaides KH, Conde-Agudelo A, et al. Vaginal progesterone decreases preterm birth $\leq 34$ weeks of gestation in women with a singleton pregnancy and a short cervix: an updated meta-analysis including data from the OPPTIMUM study. Ultrasound Obstet Gynecol 2016;48:308-17.

4. Prior JC. Progesterone for the prevention and treatment of osteoporosis in women. Climacteric 2018;21:366-74.

5. Singh M. Progesterone-induced neuroprotection. Endocrine 2006;29:271-4.

6. Cui Y, She T, Zhao H, et al. Competitive light-initiated chemiluminescent assay: using 5 - $\alpha$-dihydrotestosteroneBSA as competitive antigen for quantitation of total testosterone in human sera. Anal Bioanal Chem 2019;411:745-54.

7. Li J, Li L, Bian Y, et al. Quantitation of estradiol by competitive light-initiated chemiluminescent assay using estriol as competitive antigen. J Clin Lab Anal 2020;34:e23014

8. Clinical and Laboratory Standards Institute. User verification of precision and estimation of bias; approved guideline-3rd (ed). Wayne, PA, USA: CLSI; 2014. CLSI document EP15-A3.

9. Clinical and Laboratory Standards Institute. Evaluation

Cite this article as: Chen $\mathrm{K}, \mathrm{Wu} \mathrm{D}$, Gao M, Yan Y, Li H. Performance characteristics of the light-initiated chemiluminescent assay for quantitative determination of progesterone. Ann Transl Med 2021;9(18):1411. doi: 10.21037/ atm-21-3119 of the linearity of quantitative measurement procedures: a statistical approved guideline. Wayne, PA: CLSI, 2003.

10. CLSI EP9-A3. Method Comparision and bias estimation using patient sample. Approved GuidelineThird Edition, 2013.

11. CLSI. Evaluation of Detection Capability for Clinical Laboratory Measurement Procedures; Approved Guideline-Second Edition. CLSI document EP17-A2. Wayne, PA: Clinical and Laboratory Standards Institute, 2012.

12. Yang R, Cui L, Liu Y, et al. A hook-effect-free homogeneous light-initiated chemiluminescence assay: is it reliable for screening and the quantification of the hepatitis B surface antigen? Ann Transl Med 2020;8:606.

13. Yang S, Yang R, Zhang S, et al. Clinical diagnostic performance of light-initiated chemiluminescent assay compared with the Architect chemiluminescence immunoassay for detection of HCV antibody. J Clin Lab Anal 2019;33:e22928.

14. Monaghan PJ, Keevil BG, Trainer PJ. The use of mass spectrometry to improve the diagnosis and the management of the HPA axis. Rev Endocr Metab Disord 2013;14:143-57.

15. Kulle AE, Welzel M, Holterhus PM, et al. Principles and clinical applications of liquid chromatography - tandem mass spectrometry for the determination of adrenal and gonadal steroid hormones. J Endocrinol Invest 2011;34:702-8.

(English Language Editor: K. Brown) 